\title{
AVALIAÇÃO DA COMPATIBILIDADE ENTRE PROCESSOS PRODUTIVOS E OS ECOSSISTEMAS LOCAIS PELA DETERMINAÇÃO DA CAPACIDADE SUPORTE DOS RECURSOS HÍDRICOS: UM ESTUDO DE CASO EM SANTA CRUZ DO SUL, RS
}

\section{COMPATIBILITY ASSESSMENT BETWEEN PRODUCTION PROCESSES AND THE LOCAL ECOSYSTEMS BY THE DETERMINATION OF THE CARRYING CAPACITY OF THE WATER RESOURCES: A CASE STUDY IN SANTA CRUZ DO SUL, RS}

\author{
Adilson Ben da Costa* adilson@unisc.br \\ Daiana Dalberto*daianapru@yahoo.com.br \\ * Universidade de Santa Cruz do Sul (UNISC)
}

\begin{abstract}
Resumo: A presente pesquisa descreve a aplicação de métodos ecotoxicológicos para avaliar a capacidade de suporte do rio Pardinho, município de Santa Cruz do Sul, RS, frente ao lançamento de efluentes de diferentes origens: estação de tratamento de esgoto doméstico, frigorífico de suínos, indústria de alimentos (massas e biscoitos), indústria de curtimento de couro, indústria têxtil e lavanderia hospitalar. Os resultados obtidos permitiram identificar que em uma situação na qual qualquer um destes efluentes fosse lançado neste corpo receptor, mesmo que de forma isolada, resultaria em sérios prejuízos ambientais decorrentes de efeitos agudos e crônicos. A baixa vazão deste recurso hídrico reduz por conseqüência a sua capacidade de suportar impactos deste tipo, denunciando uma completa incompatibilidade entre as atividades geradoras destes resíduos e o ecossistema local. Assim, a alternativa para compatibilizar estes fatores passa pela otimização de processos industriais e a implantação de políticas voltadas ao reuso de águas no processo, de forma a minimizar o volume de efluente gerado e a sua ecotoxicidade.
\end{abstract}

Palavras-chave: Ecotoxicologia. Vazão. Efluentes líquidos. Impacto ambiental. Rio Pardinho

\begin{abstract}
The present research describes the application of ecotoxicological methods to assess the carrying capacity of the Pardinho river, municipality of Santa Cruz do Sul, RS, against the effluents discharge from different sources: sewage treatment station, pig refrigerator, food industry (pasta and biscuits), leather tanning industry, textile industry and hospital laundry. The results have identified that in a situation where any one of these effluents were released in this receiving body, even in isolation form, would result in serious environmental damage caused by acute and chronic effects. The low flow of this water resources reduces consequently the ability to support impacts of this type, reflecting a complete incompatibility between the generating activities of these waste and the local ecosystem. Thus, the alternative to reconcile these factors pass by the optimization of industrial processes and the implementation of policies directed at water reuse in the process, to minimize the effluent volume generated and your ecotoxicity.
\end{abstract}

Key-words: Ecotoxicology. Flow. Wastewater. Environmental impact. Pardinho River.

\section{INTRODUÇÃO}

A discussão sobre os impactos ambientais dos processos produtivos é tema 
recorrente em diferentes eventos científicos, em que novas tecnologias de produção e tratamento de resíduos são apontadas como as principais alternativas para atingir um desenvolvimento econômico sustentável.

No que se refere, particularmente, aos resíduos líquidos industriais e seu impacto sobre os recursos hídricos, estas tecnológicas buscam, tipicamente, redução do volume de resíduos gerados e da sua periculosidade.

Contudo, muitas indústrias do interior do estado do Rio Grande do Sul, lançam seus resíduos líquidos em corpos receptores de pequena vazão, apresentando por isso uma baixa capacidade de suporte, de maneira que o lançamento contínuo de resíduos mesmo que de baixa periculosidade tem resultado impactos ambientais expressivos.

Segundo Braile \& Cavalcanti (1979) existem essencialmente três situações de poluição, cada uma delas característica do estágio de desenvolvimento social e industrial: a) Poluição patogênica, caracterizada pela contaminação fecal; b) Poluição total, aquela em que os corpos receptores tornam-se realmente afetados pela carga poluidora que recebem (expressa como sólidos em suspensão e demanda de oxigênio), que normalmente ocorrem durante o desenvolvimento industrial e o crescimento das áreas urbanas; c) Poluição química, uma poluição insidiosa, causada pelo contínuo uso da água para diversos fins.

Os aspectos qualitativos são, já a bastante tempo, utilizados como parâmetros de avaliação, em que o sistema de tratamento de efluentes deve, fundamentalmente, produzir um efluente tratado dentro dos parâmetros de qualidade determinados, como por exemplo, pela resolução n 357/2005 do CONAMA Conselho Nacional do Meio Ambiente, que dispõe sobre a classificação dos corpos de água e diretrizes ambientais para o seu enquadramento, bem como estabelece as condições e padrões de lançamento de efluentes (BRASIL, 2005).

$\mathrm{O}$ artigo $8^{\circ}$, $\S 3^{\circ}$, desta resolução diz que a qualidade dos ambientes aquáticos poderá ser avaliada por indicadores biológicos, quando apropriado, utilizando-se organismos e/ou comunidades aquáticas. Ainda, no mesmo artigo, $\S 4^{\circ}$, cita que as possíveis interações entre substâncias (responsáveis por efeitos sinérgicos) bem como a presença de contaminantes não listados nesta resolução, 
passíveis de causar danos aos seres vivos, deverão ser investigadas utilizando-se ensaios ecotoxicológicos ou toxicológicos.

No estado do Rio Grande do Sul, a resolução nำ 129/2006 do CONSEMA Conselho Estadual do Meio Ambiente (RS, 2006) dispõe sobre a definição de critérios e padrões de emissão para toxicidade de efluentes líquidos. Esta descreve em seu artigo 9 que os efluentes lançados não devem causar efeito tóxico agudo ou crônico a organismos-teste pertencentes a pelo menos três níveis tróficos diferentes, de acordo com a vazão de lançamento de cada empresa e tipo de efluente.

De fato, o monitoramento tradicionalmente realizado através da avaliação de parâmetros físicos e químicos deve ser complementado com o biomonitoramento. Os parâmetros biológicos fornecem informações sobre as respostas dos organismos frente a modificações ambientais. Neste sentido, vários são os autores que têm apontado para a necessidade da inclusão do monitoramento biológico para uma real avaliação da qualidade ambiental (LOBO et al., 2006; BRENTANO \& LOBO, 2004; FENT, 2003).

Segundo Azevedo \& Chasin (2003), nos estudos de ecotoxicidade avaliam-se os efeitos causados ao organismo-teste por meio da exposição de organismos representativos do ambiente às várias concentrações do efluente ou da substância potencialmente tóxica, por um período determinado. São avaliados os efeitos agudos, onde se observa letalidade e imobilidade, e os efeitos crônicos, em que se observam alterações no crescimento, reprodução e sobrevivência.

O efeito agudo trata-se de uma resposta severa e rápida dos organismos aquáticos a um estímulo, que se manifesta, em geral, num intervalo de 0 a 96 horas. Para avaliar os efeitos agudos em testes ecotoxicológicos, geralmente usa-se a concentração letal (CL 50) ou a concentração efetiva (CE(I) 50) a 50\% dos organismos em teste. Essa é a resposta considerada mais significativa para ser explorada em uma população. Normalmente efeitos agudos de agentes tóxicos são observados no ambiente em decorrência da aplicação inadequada de agrotóxicos, ou quando indústrias liberam diretamente efluente não tratado em um corpo receptor (CETESB, 1992).

O efeito crônico se traduz pela resposta a um estímulo que continua por longo tempo, geralmente por períodos que podem abranger parte ou todo o ciclo de vida 
dos organismos. De modo geral esses efeitos são subletais e são observados em situações em que as concentrações do agente tóxico permitem a sobrevida do organismo, embora afetem uma ou várias de suas funções biológicas, tais como reprodução, desenvolvimento de ovos, crescimento e maturação. Para avaliar estes efeitos utilizam-se testes de toxicidade crônica, nos quais é determinada a concentração do agente tóxico que não causa o efeito observado (CENO Concentração de Efeito Não Observado).

Em situações onde um efluente líquido, mesmo que tratado, é lançado de forma contínua no ambiente aquático, podem ocorrer efeitos crônicos, uma vez que os organismos são expostos a baixas concentrações de determinados poluentes durante longos períodos de tempo (CETESB, 1992; KNIE \& LOPES, 2004).

No que se refere aos aspectos quantitativos, apesar de algumas resoluções ambientais considerarem informações de carga poluidora, ou seja, relacionam informações qualitativas e quantitativas, pouco se discute sobre a capacidade de suporte do corpo receptor. No estado do Rio Grande do Sul, as resoluções $n^{\circ}$ 128/2006 e n 129/2006 do CONSEMA iniciam um trabal ho de reavaliação destes aspectos para a determinação do real impacto ambiental dos efluentes industriais sobre os recursos hídricos. Ou seja, considerando a relação entre os parâmetros qualitativos e quantitativos do efluente industrial com a vazão do corpo receptor em situações de estiagem.

Segundo TUCCI (2002) e CETESB (1992), os índices utilizados para caracterizar situações de estiagem são a vazão mínima com duração de 7 dias e tempo de retorno de 10 anos $\left(Q_{7,10}\right)$ e a vazão de $90 \%$ e $95 \%$ da curva de permanência $\left(Q_{90}\right.$ e $\left.Q_{95}\right)$. As vazões mínimas $Q_{90}$ e $Q_{95}$ caracterizam situações de permanência, enquanto a $Q_{7,10}$ indica uma situação de estado mínimo (TUCCl, 2002). Segundo CETESB (1992) e VON SPERLING (2007), a $Q_{7,10}$ tem sido a vazão utilizada como referência em estudos para definição de critérios de emissão de efluentes líquidos tóxicos

Para a determinação destes valores de vazão deve-se dispor de registros fluviométricos históricos do recurso hídrico receptor dos resíduos, no entanto, estas informações freqüentemente inexistem, impedindo a determinação destes índices. Contudo, estes valores podem ser estimados pelo método de regionalização de 
vazões, no qual as informações providas de estações fluviométricas de características similares à em estudo, são transferidas para esta pela correlação de valores de descarga específica $\left(\mathrm{m}^{3} \mathrm{~s}^{-1} \mathrm{~km}^{-2}\right)$ (VON SPERLING, 2007).

Neste contexto, este estudo descreve a aplicação de métodos ecotoxicológicos para avaliar a capacidade de suporte de um recurso hídrico frente ao lançamento de efluentes de diferentes origens. Pretende-se assim, contribuir para um modelo mais sustentável de desenvolvimento industrial focado na seleção do corpo receptor mais adequado a um determinado perfil de resíduo industrial, de forma a minimizar impactos ambientais.

\section{METODOLOGIA}

Este estudo foi dividido em duas etapas, a primeira focada na compilação de dados ecotoxicológicos de diferentes fontes poluidoras locadas no município de Santa Cruz do Sul, RS, bem como das características hidrológicas do rio Pardinho. $\mathrm{Na}$ segunda etapa, foram determinadas as condições de descarte destes efluentes caso fossem lançados em um determinado ponto do rio Pardinho, principal recurso hídrico do município.

\subsection{Compilação de dados históricos}

Os resultados ecotoxicológicos foram compilados de diferentes estudos realizados no Laboratório de Ecotoxicologia da UNISC, entre os anos de 2003 e 2009, os quais descrevem as características ecotoxicológicas de efluentes de atividades distintas, a saber: Estação de tratamento de esgoto doméstico, frigorífico de suínos, indústria de alimentos (massas e biscoitos), indústria de curtimento de couro, indústria têxtil e lavanderia hospitalar. Estes resíduos foram coletados após seu tratamento nos sistemas utilizados nas respectivas unidades geradoras.

As características hidrológicas do rio Pardinho foram determinadas a partir dos dados de vazão da Estação Fluviométrica Santa Cruz - Montante (código 85830000), no rio Pardinho, monitorada pela ANA - Agência Nacional de Águas 
(ANA, 2007), Figura 1. Esta base de dados permitiu a determinação do perfil de vazão do rio Pardinho no período entre 1978 e 2005.

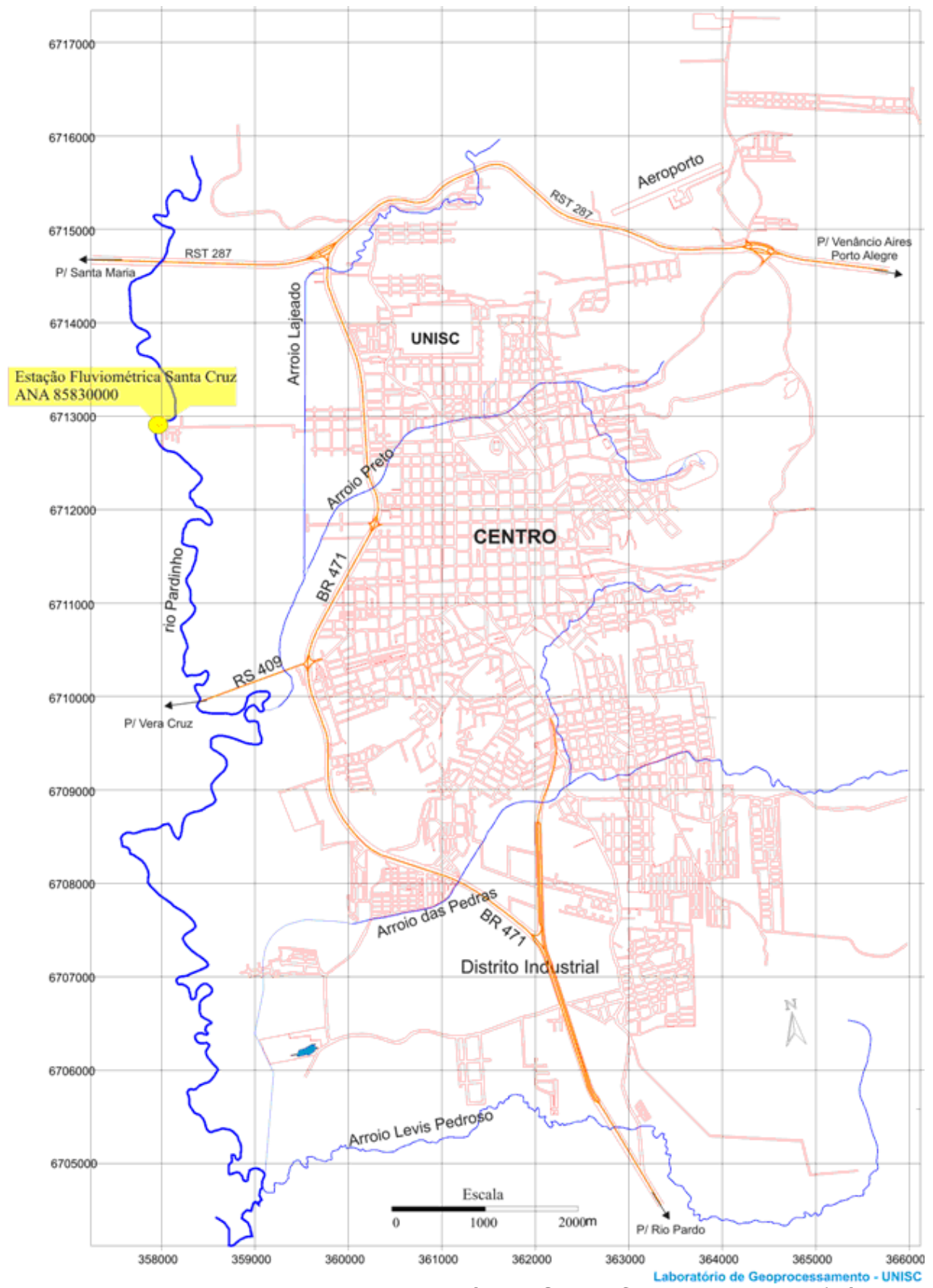

Figura 1 - Localização da Estação Fluviométrica Santa Cruz - Montante (código 85830000), no Município de Santa Cruz do Sul, RS, Brasil

\subsection{Determinação da vazão mínima}

Para determinação da $Q_{7,10}$ foram computadas as médias móveis das vazões médias diárias com janela de 7 dias ao longo de cada ano hidrológico, conforme 
metodologia para vazões mínimas descrita em TUCCI (2002) e VON SPERLING (2007).

\subsection{Processamento da informação}

A partir dos resultados das determinações da $\mathrm{CE}(\mathrm{I}) 50$ 48h foi utilizada uma escala de toxicidade relativa, conforme mostra a Tabela 1 (LOBO et al., 2006).

Tabela 1- Escala de toxicidade relativa para CE50 48h (\%) com Daphnia magna.

\begin{tabular}{ccc}
\hline Percentil & CE(I)50 & Toxicidade relativa \\
\hline $25^{\circ}$ & $<25$ & Extremamente tóxica \\
$50^{\circ}$ & $25-50$ & Altamente tóxica \\
$75^{\circ}$ & $50-75$ & Medianamente tóxica \\
- & $>75$ & Pouco tóxica \\
\hline
\end{tabular}

Fonte: (LOBO et al., 2006)

Para a determinação da capacidade de suporte do rio Pardinho foi calculada a concentração do efluente no corpo receptor (CER), para cada efluente investigado, conforme a Eq. 1 (CETESB, 1992), onde Qe representa a vazão do efluente industrial, e $Q_{7,10}$ a vazão mínima com duração de 7 dias e tempo de retorno de 10 anos na Estação Fluviométrica Santa Cruz.

$\mathrm{CER}=\frac{\mathrm{Qe}}{\mathrm{Q} 7,10+\mathrm{Qe}} \times 100$

Para estimar o impacto de cada efluente no rio Pardinho foi avaliada a relação entre os resultados de ecotoxicidade do efluente, $C E(I) 50$ 48h, e concentração do efluente no corpo receptor (CER), considerando a relação proposta pela CETESB Companhia de Tecnologia de Saneamento Ambiental do Estado de São Paulo, que descreve que para testes de toxicidade aguda, ao nível de $1 / 3$ da CE(I)50 praticamente cessam os efeitos tóxicos (CETESB, 1992). Assim, para prevenir efeitos agudos ao corpo receptor à concentração do efluente neste deve ser igual ou inferior a 1/3 CE(I)50 (Eq. 2). 
$\mathrm{CER} \leq \frac{C E 50}{3}$

Além disto, segundo CETESB (1992), a relação entre a CE(I)50 e CENO está, tipicamente, na ordem de 1/10 (Eq. 3). Portanto, com a obtenção dos dados de toxicidade aguda é possível estimar efeitos crônicos ao ambiente aquático pela Eq. 4, a qual descreve que para prevenir efeitos crônico ao ambiente a CER deve ser igual ou inferior a $1 / 10$ da $C E(I) 50$.

$$
\begin{aligned}
& \mathrm{CENO}=\frac{C E 50}{10} \\
& \mathrm{CER} \leq \frac{C E 50}{10}
\end{aligned}
$$

Contudo, a estimativa apresentada se aplica às situações de mistura completa do efluente no corpo receptor, baseando-se na utilização de três espécies, no mínimo, de organismos aquáticos, bem como na suposição de que não exista variabilidade na toxicidade do efluente ao longo do tempo. De fato, a utilização de um número reduzido de espécies pode gerar uma razoável incerteza quando se efetua uma estimativa de impacto, pois a sensibilidade entre as diversas espécies de organismos pode variar em torno de dez vezes.

Da mesma forma, a variabilidade na toxicidade dos efluentes pode apresentar variações ao redor de dez vezes.

Sendo assim, estes fatores de incerteza devem ser considerados, de forma que na avaliação da capacidade de suporte do rio Pardinho as equações 2 e 4 foram substituídas pelas eqs. 5 e 6 abaixo, conforme orientação de CETESB (1992).

$$
\begin{aligned}
& \text { CER } \leq \frac{C E 50}{300} \\
& C E R \leq \frac{C E 50}{1000}
\end{aligned}
$$


Neste contexto, a capacidade de suporte do recurso hídrico corresponde à vazão de efluente industrial que este suporta receber, sem que a concentração do efluente neste, supere o determinado na equação 5 e 6 para efeitos agudos e crônicos respectivamente.

\section{RESULTADOS}

\subsection{Características hidrológicas do Rio Pardinho}

A partir da compilação dos dados históricos de vazão do rio Pardinho, foi confeccionado um histograma de vazão correspondente ao período entre 01/01/1996 e 31/12/2005, Figura 2. Neste período, 3469 determinações de vazão foram realizadas, determinando uma vazão média de $21,1 \pm 33,4 \mathrm{~m}^{3} \mathrm{~s}^{-1}$, com valores de máximo e mínimo de 270,4 e $0,187 \mathrm{~m}^{3} \mathrm{~s}^{-1}$, respectivamente.



Figura 2 - Histograma dos dados de vazão do rio Pardinho no período 01/01/1996 e 31/12/2005, na Estação Fluviométrica Santa Cruz - Montante (código 85830000), no Município de Santa Cruz do Sul, RS, Brasil

Posteriormente foram computadas as médias móveis das vazões médias diárias com janela de 7 dias ao longo de cada ano hidrológico, conforme metodologia para vazões mínimas descrita em Tucci (2002). A Figura 3 apresenta a curva de regressão da vazão mínima de sete dias e a respectiva equação para o rio Pardinho. 


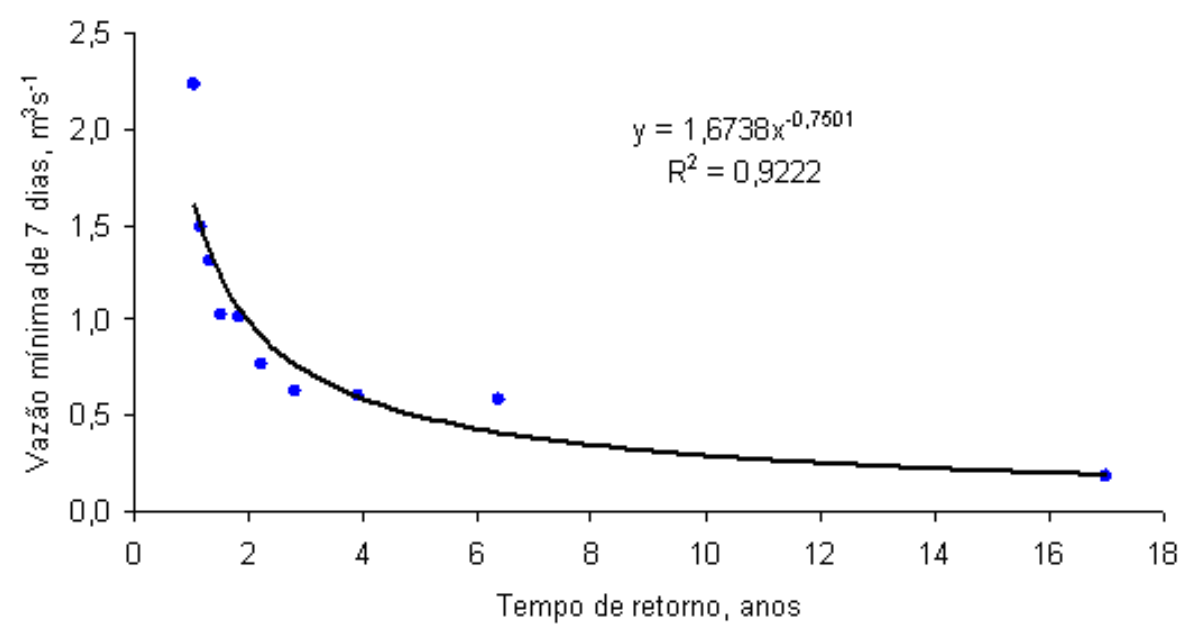

Figura 3 - Curva de regressão para a vazão mínima de sete dias para o rio Pardinho na estação fluviométrica Santa Cruz - Montante (código 85830000), no Município de Santa Cruz do Sul, RS, Brasil

A equação de regressão obtida (Eq. 7), foi utilizada para determinar a vazão mínima com duração de 7 dias e tempo de retorno de 10 anos $\left(Q_{7,10}\right)$ para o rio Pardinho.

$\mathrm{Q} 7,10=1,6738 x^{-0,7501}$

A Tabela 2 resume as caracterísitcas hidrológicas determinadas para o rio Pardinho na Estação Fluviométrica Santa Cruz - Montante (código 85830000), no Município de Santa Cruz do Sul, RS, Brasil.

Tabela 2 - Características hidrológicas determinadas para o rio Pardinho na Estação Fluviométrica Santa Cruz - Montante (código 85830000), no Município de Santa Cruz do Sul, RS, Brasil

\begin{tabular}{lcc}
\hline \multicolumn{1}{c}{ Parâmetro } & Unidade & Resultados \\
\hline Área de drenagem & $\mathrm{km}^{2}$ & 784 \\
Vazão máxima & $\mathrm{m}^{3} \mathrm{~s}^{-1}$ & 270,4 \\
Vazão mínima & $\mathrm{m}^{3} \mathrm{~s}^{-1}$ & 0,187 \\
Vazão média & $\mathrm{m}^{3} \mathrm{~s}^{-1}$ & $21,1 \pm 33,9, \mathrm{n}=3469$ \\
$\mathrm{Q}_{7,10}$ & $\mathrm{~m}^{3} \mathrm{~s}^{-1}$ & 0,298 \\
$\mathrm{Q}_{7,10}$ & $\mathrm{~m}^{3} \mathrm{dia}^{-1}$ & 25747,2 \\
\hline
\end{tabular}




\subsection{Características dos efluentes investigados}

A Tabela 3 descreve as características físicas, químicas e ecotoxicológicas dos efluentes investigados. Os resultados de vazão correspondem à vazão máxima de operação permitida nas licenças de operação (LO) de cada empreendimento. Os valores de DQO - Demanda química de oxigênio e DBO - Demanda bioquímica de oxigênio e $\mathrm{CE}(\mathrm{I}) 50$ foram compilados junto ao Laboratório de Ecotoxicologia da UNISC. Já, os valores de CENO foram determinados conforme a Eq. 3.

Dos efluentes pesquisados, apenas as amostras da indústria têxtil e da indústria de curtimento de couro aparentaram valores de DQO e DBO fora dos limites máximos estipulados pela resolução n 128/2 006 do CONSEMA.

Os resultados para $\mathrm{CE}(\mathrm{I}) 50$ revelaram que os efluentes da indústria de alimento e da indústria frigorífica não apresentam toxicidade significativa CE(I)50>100. O efluente da ETE apresentou CE(I)50 de $66 \%$ e o efluente têxtil $\mathrm{CE}(\mathrm{I}) 50$ de $54 \%$, ambos permanecendo na faixa de moderadamente tóxico. Os efluentes da indústria de couro e da lavanderia hospitalar são os que merecem um destaque maior, visto que eles apresentaram-se extremamente tóxicos, com CE(I)50 de $8,8 \%$ e $0,6 \%$, respectivamente (Figura 4 ).

Tabela 3 - Características físicas, químicas e ecotoxicológicas dos efluentes avaliados

\begin{tabular}{|c|c|c|c|c|c|}
\hline Origem do efluente & $\begin{array}{l}\text { Vazão } \\
\text { m }^{3} \text { dia }^{-1} \\
\end{array}$ & $\begin{array}{l}\mathrm{DQO} \\
\mathrm{mgL}^{-1}\end{array}$ & $\begin{array}{l}\mathrm{DBO} \\
\mathrm{mgL}^{-1}\end{array}$ & $\begin{array}{c}\text { CE(I) } 50 \\
\%\end{array}$ & $\begin{array}{c}\text { CENO } \\
\%\end{array}$ \\
\hline $\begin{array}{l}\text { ETE - Estação de } \\
\text { tratamento de esgoto } \\
\text { doméstico }\end{array}$ & 670 & 114 & 36 & 66 & 6,6 \\
\hline $\begin{array}{l}\text { FS - Frigorífico de } \\
\text { suínos }\end{array}$ & 360 & 111 & 40 & $>100$ & $>10$ \\
\hline $\begin{array}{lll}\text { IA } \quad \text { Indústria } & \text { de } \\
\text { alimentos (massas } & \text { e } \\
\text { biscoitos) } & & \end{array}$ & 40 & 15 & $\begin{array}{c}\text { Não } \\
\text { determinado }\end{array}$ & $>100$ & $>10$ \\
\hline $\begin{array}{l}\text { IC - Indústria de } \\
\text { curtimento de couro }\end{array}$ & 432 & 328 & 129 & 8,8 & 0,88 \\
\hline IT - Indústria têxtil & 40 & 589 & 172 & 54 & 5,4 \\
\hline $\begin{array}{ll}\text { LH - } & \text { Lavanderia } \\
\text { hospitalar } & \end{array}$ & 50 & $\begin{array}{c}\text { Não } \\
\text { determinado }\end{array}$ & 34 & 0,6 & 0,06 \\
\hline
\end{tabular}




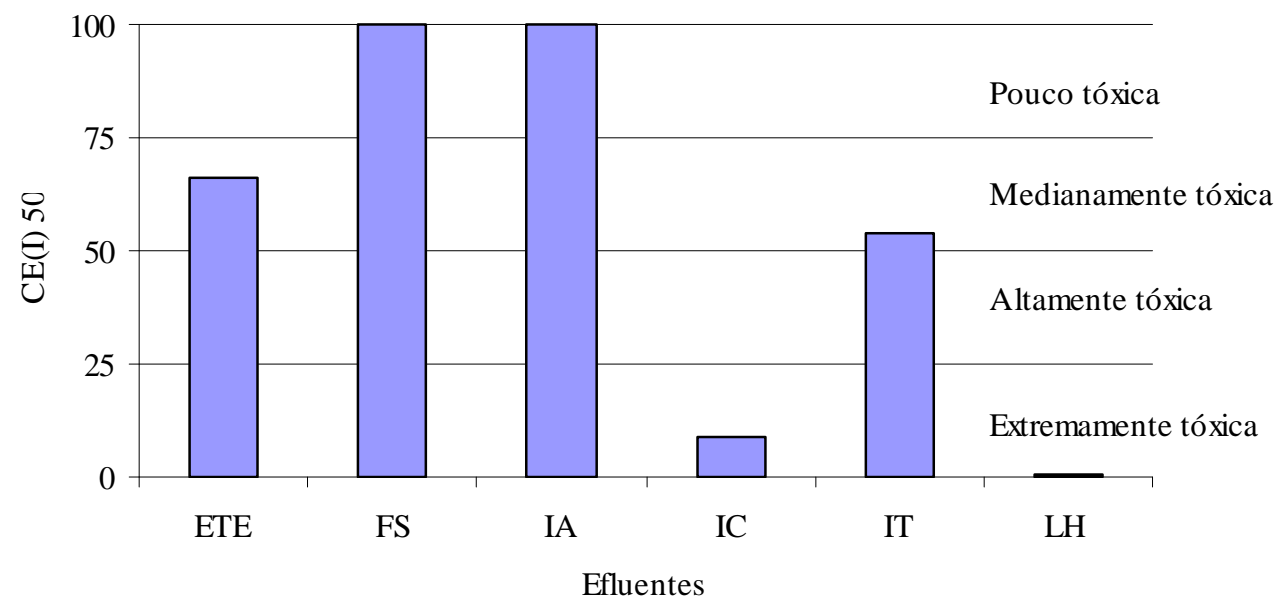

Figura 4 - Resultado dos testes de toxicidade para os diferentes efluentes avaliados

A Tabela 4 descreve os resultados de concentração de efluente no rio Pardinho (CER) em situações para prevenir efeito agudo (CER-EA) e efeito crônico (CER-EC), bem como apresenta a estimativa de vazão ideal destes efluentes (Qe ideal), que corresponde a capacidade de suporte.

Os resultados obtidos indicaram que todos os resíduos avaliados, resultam em riscos agudos e crônicos ao ecossistema aquático do rio Pardinho mesmo que lançados separadamente neste corpo receptor.

Tabela 4 - Resultados de concentração de efluente no corpo receptor (CER) em situações para prevenir efeito agudo (CER-EA) e efeito crônico (CER-EC) e vazão ideal dos efluentes (Qe ideal)

\begin{tabular}{lccccccc}
\hline & $\begin{array}{c}\mathrm{CE}(\mathrm{I}) 50 \\
\%\end{array}$ & $\begin{array}{c}\mathrm{Q}_{7,10} \\
\mathrm{~m}^{3} \mathrm{dia}^{-1}\end{array}$ & $\begin{array}{c}\text { Qe } \\
\mathrm{m}^{3} \mathrm{dia}^{-1}\end{array}$ & $\begin{array}{c}\text { CER } \\
\%\end{array}$ & $\begin{array}{c}\text { CER-EA } \\
\%\end{array}$ & $\begin{array}{c}\text { CER-EC } \\
\%\end{array}$ & $\begin{array}{c}\text { Qe ideal } \\
\mathrm{m}^{3} \mathrm{dia}^{-1}\end{array}$ \\
\hline ETE & 66 & 25747,2 & 670 & 2,53 & $\leq 0,220$ & $\leq 0,066$ & $\leq 17,0$ \\
FS & ST $(\geq 100)$ & 25747,2 & 360 & 1,38 & $>0,33$ & $>0,10$ & $>25,8$ \\
IA & ST $(\geq 100)$ & 25747,2 & 40 & 0,16 & $>0,33$ & $>0,10$ & $>25,8$ \\
IC & 8,8 & 25747,2 & 432 & 1,65 & $\leq 0,029$ & $\leq 0,009$ & $\leq 2,3$ \\
IT & 54 & 25747,2 & 40 & 0,16 & $\leq 0,180$ & $\leq 0,054$ & $\leq 13,9$ \\
LH & 0,6 & 25747,2 & 50 & 0,19 & $\leq 0,002$ & $\leq 0,001$ & $\leq 0,2$ \\
\hline
\end{tabular}

A Figura 5 descreve a relação entre a vazão atual destes efluentes e a capacidade de suporte deste recurso hídrico, permitindo identificar nos efluentes da indústria de curtimento de couro e da lavanderia hospitalar a pior relação de sustentabilidade, nas quais uma redução em mais de $99 \%$ na vazão destes 
efluentes seria necessária para evitar efeitos ecotoxicológicos crônicos ao ecossistema.

— Vazão atual $\square$ Capacidade de suporte



Figura 5 - Valores de vazão dos efluentes industriais avaliados e respectiva capacidade de suporte do rio Pardinho na estação fluviométrica Santa Cruz

\section{CONCLUSÕES}

Os resultados obtidos permitiram identificar que em uma situação na qual qualquer um destes efluentes fossem lançados neste ponto do rio Pardinho, mesmo que de forma isolada, resultaria em sérios prejuízos ambientais decorrentes de efeitos agudos e crônicos.

A baixa vazão deste recurso hídrico reduz por conseqüência a sua capacidade de suportar impactos deste tipo, denunciando uma completa incompatibilidade entre as atividades geradoras destes resíduos e o ecossistema local.

Assim, a alternativa para compatibilizar estes fatores passa pela otimização de processos industriais e a implantação de políticas voltadas ao reuso de águas no processo, de forma a minimizar o volume de efluente gerado e a sua ecotoxicidade.

Além disto, ressaltasse a necessidade de que em estudos de planejamento de ocupação do solo por atividades industriais, a disponibilidade hídrica local seja considerada não apenas do ponto de vista de matéria prima ou insumo do processo, mas também como corpo receptor de resíduos. Assim, a determinação da capacidade máxima de suporte do recurso hídrico tornar-se-á de falo um fator 
determinante na localização espacial de atividades industriais minimizando impactos sobre os ecossistemas locais.

\section{REFERÊNCIAS}

AGÊNCIA NACIONAL DE ÁGUAS (ANA). Sistema de informações hidrológicas da ANA Disponível em: <http://hidroweb.ana.gov.br>. Acesso em: 17 dez. 2007.

ARAGÃO, M. A. \& ARAÚJO, R. P. A. Métodos de ensaios de toxicidade com organismos aquáticos. p. 117-152. In: ZAGATTO, P. A.; BERTOLETTI, E. (Org.). Ecotoxicologia aquática: princípios e aplicações. São Carlos : RiMa, 2006. 478 p.

AZEVEDO, F. A. \& CHASIN, A. A. M. (Org.). As bases toxicológicas da ecotoxicologia. São Carlos: RiMa, 2003. 340 p.

BRAILE, P. M. \& CAVALCANTI, J. E.W. A. Manual de tratamento de águas residuárias industriais. São Paulo: CETESB, 1979. 764 p.

BRASIL. Resolução Conselho Nacional do Meio Ambiente no 357, de 17 de março de 2005. Diário Oficial da União, Brasília, DF, 18 de março de 2005.

BRENTANO, D. M. \& LOBO, E. A. Avaliação ecotoxicológica do processo produtivo de um curtume, utilizando Daphnia magna Straus como organismo teste. Revista Brasileira de Toxicologia, v. 17, n. 2, p. 13-18, 2004.

COMPANHIA DE TECNOLOGIA DE SANEAMENTO AMBIENTAL (CETESB). Métodos de avaliação da toxicidade de poluentes a organismos aquáticos. São Paulo: CETESB, 1992. 312 p.

FENT, KARL. Ecotoxicological Problems associated with contaminated sites. toxicology letters, v.140, p. 353-365. 2003.

KNIE, J. L. W. \& LOPES, E. W. B. Testes ecotoxicológicos: métodos, técnicas e aplicações. Florianópolis: FATMA / GTZ, p. 289. 2004.

LOBO, E. A.; RATHKE, F.S.; BRENTANO, D. M. Ecotoxicologia aplicada: o caso dos produtores de tabaco na bacia hidrográfica do Rio Pardinho, RS, Brasil. In: ETGES, V. E.; FERREIRA, M. A. F. A produção do tabaco: impacto no ecossistema e na saúde humana na região de Santa Cruz do Sul/RS. Santa Cruz do Sul: EDINISC, 2006. p.41-68.

RIO GRANDE DO SUL (RS). Conselho Estadual do Meio Ambiente (CONSEMA) Resolução no 128, de 24 de novembro de 2006.

Resolução no 129, de 24 de novembro de 2006. 
TUCCI, C. E. M. Regionalização de vazões. Porto Alegre: Ed. da UFRGS, 2002.

VON SPERLING, M. Estudos e modelagem da qualidade da água de rios. Belo Horizonte: UFMG, 2007. 588 p.

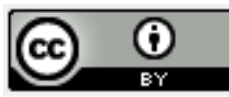

Artigo recebido em 30/12/2009 e aceito para publicação em 03/10/2010. 